\title{
Lumbar Scheuermann conservative treatment allows a proper vertebral body growth and spinal configuration: a case series
}

\section{Fusco*, S Atanasio, F Zaina and S Negrini}

\author{
Address: ISICO (Italian Scientific Spine Institute), Via Roberto Bellarmino 13/1, 20141 Milan, Italy \\ Email: C Fusco* - claudia.fusco@isico.it \\ * Corresponding author
}

from 6th International Conference on Conservative Management of Spinal Deformities

Lyon, France. 21-23 May 2009

Published: I4 December 2009

Scoliosis 2009, 4(Suppl 2):O58 doi:I0.I I86/I748-7|6I-4-S2-O58

This abstract is available from: http://www.scoliosisjournal.com/content/4/S2/O58

(C) 2009 Fusco et al; licensee BioMed Central Ltd.

\section{Objectives}

The objecting of this study was to verify the efficacy of brace treatment for lumbar Scheuermann disease on radiographic parameters.

\section{Background}

Lumbar Scheuermann (LS) is an atypical localization of Scheuermann disease. It has been seldom studied, and little is known about its conservative treatment.

\section{Methods}

We retrospectively observed 13 patients with the diagnosis of LS. 7 of them needed bracing because of lumbar kyphosis, while the others were treated only with physical exercises to control pain and prevent deformity. All patients treated with bracing ( 3 males and 4 females, average age 13.5 years) presented at first observation with back pain, lumbar kyphosis, and a radiographic image of lumbar bone damage typical of Scheuermann disease. 5 of them started treatment with 20 or 23 hours/day of bracing and reached the end of treatment after an average of 2.5 years through a period of progressive brace weaning, and 2 are still in treatment.

\section{Results}

The two treatment groups were significantly different at the start. Both treatments produce a fast disappearance of pain. With bracing, a progressive achievement of a proper sagittal outline was achieved, with a good radiographic reconstruction of lumbar vertebral bodies. Distances from plumbline improved, showing a gradual increase of lumbar lordosis. 2 patients are still in treatment, they are now pain free, and clinical and radiographic data suggest an improvement of lumbar kyphosis.

\section{Conclusion}

These observations show that bracing can effectively correct LS, allowing proper lumbar vertebral body growth, while exercises can control pain and possible worsening. 